\title{
BMJ Open Informal and formal care preferences and expected willingness of providing elderly care in Germany: protocol for a mixed-methods study
}

\author{
Lea de Jong, ${ }^{1}$ Marika Plöthner, ${ }^{1}$ Jona Theodor Stahmeyer, ${ }^{2}$ Sveja Eberhard, ${ }^{2}$ \\ Jan Zeidler, ${ }^{1}$ Kathrin Damm ${ }^{1}$
}

To cite: de Jong L, Plöthner M, Stahmeyer JT, et al. Informal and formal care preferences and expected willingness of providing elderly care in Germany: protocol for a mixedmethods study. BMJ Open 2019;9:e023253. doi:10.1136/ bmjopen-2018-023253

- Prepublication history for this paper is available online. To view these files, please visit the journal online (http://dx.doi. org/10.1136/bmjopen-2018023253).

Received 28 March 2018 Revised 22 November 2018 Accepted 26 November 2018

Check for updates

(c) Author(s) (or their employer(s)) 2019. Re-use permitted under CC BY-NC. No commercial re-use. See rights and permissions. Published by BMJ.

${ }^{1}$ Center for Health Economics Research Hannover (CHERH), Leibniz University of Hannover, Hannover, Germany

${ }^{2}$ Health Services Research Unit, AOK Niedersachsen, Hannover, Germany

Correspondence to

Lea de Jong; Idj@cherh.de

\section{ABSTRACT}

Introduction In Germany, the number of elderly people in need of care is expected to increase from 2.4 million in 2015 to 3.2 million in 2030. The subsequent rise in demand for long-term care facilities is unlikely to be met by the current care structures and available staff. Additionally, many Germans still prefer to be cared for at home for as long as possible. In light of recent changes, such as increasing employment rates of women and growing geographical distances of family members, informal caregiving becomes more challenging in the future. The aim of this study is to explore preferences for informal and formal care services in the German general population, as well as the expected willingness of providing elderly care.

Methods and analysis A mixed-methods approach will be used to explore care preferences and expected willingness of providing elderly care in the German general population. A systematic literature review will be performed to provide an overview of the current academic literature on the topic. Qualitative interviews will be conducted with informal caregivers, care consultants and people with no prior caregiving experiences. A labelled discrete choice experiment will be designed and conducted to quantitatively measure the preferences for informal and formal care in the German general population. People between 18 and 65 years of age will be recruited in cooperation with a (regional) statutory health insurance (AOK Lower Saxony). A mixed multinomial logit regression model and a latent class finite mixture model will be used to analyse the data and test for subgroup differences in care preferences.

Ethics and dissemination The study has been approved by the Committee for Clinical Ethics of the Medical School in Hannover. Data will be treated confidential to ensure the participants' anonymity. The results will be discussed and disseminated to relevant stakeholders in the field.

Trial registration number DRKS00012266.

\section{INTRODUCTION}

Demographic developments towards an increasingly ageing population place significant pressure on national health systems to adequately prepare for future challenges.
Strengths and limitations of this study

- This is the first study based on a (labelled) discrete choice experiment design to elicit care preferences of the German general population, as well as the expected willingness of providing elderly care.

- This method enables an inferability to the relative importance and value people place on different care characteristics, as they need to make trade-offs between a number of attributes and their levels in deciding between two hypothetical care scenarios.

- Results can be used to better tailor existing care structures and payment systems in Germany.

- However, the study focuses on the German general population. Transferability of the results needs to be tested with transnational comparisons.

- The design of the discrete choice experiment demands participants to make decisions based on what they think and thus might not predict real behaviours.

More specifically, health systems will likely face growing healthcare costs due to rising numbers of chronic diseases and people in need of care, while reductions in revenues for long-term care insurance are expected as a consequence of lower birth rates. ${ }^{1}$ The latest statistics for the year 2015 found that 2.4 million Germans aged 65 years and older were in need of care. ${ }^{2}{ }^{3}$ While a need for care can arise at any age, we will only focus on the growing dependency on care of the elderly in this study. Future projections estimate an increase of people in need of care to 3.2 million by 2030 and 4.4 million by $2060 .^{3-5}$

Of the currently 2.4 million elderly people in need of care, the majority of Germans are being cared for at home through relatives or friends (informal care) and/or outpatient services. ${ }^{26}$ To exemplify, $79 \%$ of the age group 60-69 and 57\% of elderly aged $90+$ are being cared for at home. ${ }^{6}$ It is often reported that the majority of people in need of care 
prefer to stay in their familiar surroundings for as long as possible to maintain a high degree of autonomy and their social ties. ${ }^{78}$ Home care is also encouraged by German health policy and political efforts, as it is less costly for the state and the social security system. ${ }^{9}$ However, these political efforts do not necessarily coincide with the required support and incentives of providing care at home.

Different economic theories exist that aim to explain the decision to provide informal care. This needs to be seen against the background that several studies have stressed the extreme burden caregivers are under as a result of time-consuming and straining work. ${ }^{10}{ }^{11}$ Others have also found positive outcomes of providing informal care, such as increased self-esteem. ${ }^{12}$ In a model of altruistic behaviour, the benefits or utility of caregiving (eg, increased self-esteem) need to outweigh the costs and burden to warrant the decision to provide informal care. Other behavioural models are based on strategic exchanges between parents and their children in the form of financial incentives for caregiving to explain the decision-making process. ${ }^{13}$ Studies have found determining factors of making use of home care services to include having children, previous experience in providing informal care, as well as the proximity of family resources. ${ }^{813-15}$

In light of changing family dynamics, such as increasing employment rates of women and growing geographical distances of family members, while male labour participation and involvement as informal caregivers has remained nearly consistent, some experts expect the rates of informal caregiving to decrease in the future. ${ }^{89}$ However, the subsequent increase in demand for long-term care facilities is unlikely to be met by the current number of facilities and qualified staff members. ${ }^{9}$ Thus, as informal caregiving will likely become more challenging to provide and with the number of people in need of care continuously increasing, sustainable solutions are needed.

\section{Aims}

The objective of this study is to explore preferences for informal and formal (outpatient) care services in the German general population, as well as the expected willingness of providing elderly care. First, we would like to survey the general population's preferences for providing informal and formal care services for their relative(s) in need of care. Second, we seek to explore any differences in preferences between an own hypothetical dependency on care compared with their relatives' need for care. Lastly, we look to find and provide recommendations on ways to optimise care by considering people's preferences. We will place particular emphasis on the analysis of subgroup differences in care preferences, such as age, gender, previous caregiving experiences, migration background or occupation. This study will be the first to use a discrete choice experiment (DCE) as a validated stated preference method to measure the caregiving preferences of the German general population. ${ }^{16}{ }^{17}$ Analysing people's preferences presents an important source of information and indication towards better tailoring current care structures and payment systems.

\section{METHODS AND ANALYSIS}

A mixed-methods approach will be used to explore informal and formal care preferences and expected willingness of providing elderly care in Germany. In particular, a systematic literature review, face-to-face interviews and a DCE will be conducted to assess people's care preferences. Face-to-face interviews will be used to ascertain a range of experiences and explore challenges people face when it comes to caregiving. These insights will then be used to inform the design of the DCE. The International Society for Pharmacoeconomics and Outcomes Research (ISPOR) guidelines for good research practices for conjoint analysis in health will be followed for the DCE. ${ }^{18}$

\section{Systematic literature review}

To create a guideline for the qualitative interviews and design the DCE, we will perform a systematic literature review on published academic studies researching preferences for informal and formal care services. The review will be carried out in accordance with the Preferred Reporting Items for Systematic Reviews and Meta-Analyses (PRISMA) guidelines. ${ }^{19}$ The selection process will be based on predefined inclusion and exclusion criteria. The electronic databases PubMed, Scopus and Dimdi (German Institute of Medical Documentation and Information) will be used with a predefined search strategy. A list of search terms of the four main concepts 'informal and formal care', 'long term care', 'preferences' and 'age of interest' will be created and connected with the Boolean operators AND and OR. Truncations (*) will be used to find all forms of the word. English and German search terms will be employed in the database search. No specific time frame will be set for the database search. After removing duplicates, two independent reviewers will perform the selection process. The first selection of articles will be based on screening the titles and abstracts. If the inclusion criteria are met, the full text of the articles will be read and checked for final inclusion. In case of disagreement, a third reviewer will be consulted. The database search will additionally be complemented by handsearching the reference lists of the included literature. The quality of the systematic literature review will be tested with the PRISMA checklist. ${ }^{19}$

\section{Face-to-face interviews}

Semistructured, guideline-based face-to-face interviews will be conducted in the region of Hannover, Germany to explore people's views and caregiving preferences. Eligible interviewees will receive detailed information beforehand concerning the aim and scope of the study, as well as any data management issues. Interviews will only be conducted after a written informed consent was signed. For the interviews, informal caregivers, care consultants and people with no prior caregiving experiences 
will be recruited. For this purpose, primarily self-help groups, care consultancies and care support points will be identified in the region of Hannover and subsequently contacted. Maximum variation purposive sampling will be used to identify heterogeneous participants for the qualitative interviews. ${ }^{20}$ The total sample size will be based on the principle of theoretical saturation, meaning no new views on the topic are expressed. ${ }^{21}$

One experienced researcher (LdJ) will conduct all interviews to ensure homogeneity. The researcher will make sure beforehand that each participant is familiar with the study's aims and the voluntary nature of participating in it. The guideline will be used for each interview and continually revised to incorporate new points of interest identified during the interviews. Each interview will be audio recorded and subsequently transcribed. In order to analyse the transcripts of the audio recording context-oriented, interviewees will be asked to fill out a questionnaire following the interview, disclosing essential sociodemographic factors such as age, gender, profession, previous and/or current caregiving experiences as well as the geographical distance to the person in need of care. The planned expenditure of time is set at $30 \mathrm{~min}$, as the target audience of informal caregivers is unlikely to be able to spare too much time for participating in interviews.

The guideline interview questions will be based on information collected by means of the systematic literature review. To test the comprehensibility of the interview questions, a group of experts and randomly selected lay people will be consulted. During the interviews, we will ask participants about the current structure of care they provide and if this type of care reflects their wishes as well as the wishes of the person in need of care. We additionally seek to know the perceived challenges of providing care and any observed effects on their time and cost structure. One central question will be people's wishes and preferences for their own hypothetical care and any perceived differences to the provision of care for their relatives. An interesting subquestion at this point will be the responsibility for providing care, that is, if people perceive this to be a familial or societal obligation. In the execution of care, we seek to ask people's preferences for care provided by other people versus potential technical support. Furthermore, we will ask people for suggestions for improving the current care structure in Germany.

\section{Interview analysis}

With the informed consent of each participant, all interviews will be recorded, transcribed and subsequently analysed. All transcripts will be entered into MAXQDA V.11 and reviewed line by line. For the analysis of the transcripts, a qualitative content analysis will be performed by two independent researchers based on Mayring. ${ }^{22}$ The content analysis will take on a directed approach, making use of deductive categories identified in the interview guide, while at the same time leaving room for further inductive categories generated during the analysis of the interview transcripts. ${ }^{23}$ A codebook will additionally be created for the two researchers performing the analysis. Findings will be crucial in informing the design of the DCE, in particular, the generation of attributes for the DCE.

\section{Discrete choice experiment}

Description of the DCE

The DCE is a stated preference method, combining knowledge from random utility theory, experimental design theory, consumer theory and econometric analysis. ${ }^{24}$ The method of DCE has been increasingly applied and deemed useful in the field of healthcare research to elicit people's preferences. ${ }^{25}{ }^{26}$ In a DCE, people are asked to choose between two or more alternative scenarios. The underlying assumptions of a DCE are that any intervention or service looked at can be described by its attributes or characteristics and that people value these attributes differently depending on their levels. ${ }^{27}$ The attributes and its different levels are then comprised to several scenarios, of which people are asked to choose one based on their preference. This method enables an inferability to the relative importance and value people place on different attributes, as these need to make trade-offs between the several attributes and their levels in their decision-making process. ${ }^{18}$

\section{Design of the DCE}

We will conduct a DCE to measure the caregiving preferences in the German general population. In the process of constructing an optimal or nearly optimal experimental design, two statistical issues need to be examined. Namely, identification meaning the ability to obtain independent and unbiased parameter estimates and efficiency as the precision with which such effects are estimated. ${ }^{17}$ Several authors argue that design identification should take priority, as efficiency can be improved later by, for instance, increasing the sample size. However, identification errors in the design cannot be altered retrospectively and are likely to produce biased and confounded results. ${ }^{1728}{ }^{29}$ Statistical efficiency and response efficiency need to be balanced to maximise the precision of parameter estimates. ${ }^{30}$ We will use the D-efficiency criterion as a measure of statistical efficiency, while blocking certain choice sets will be used to increase response efficiency by reducing the information load of participants. The D-efficiency criterion has been increasingly used to measure statistical efficiency when aiming to create optimal designs with an efficiency of $100 \%$. Thus, we will create choice sets that minimise the D-error, which in turn maximises the D-efficiency. ${ }^{26}{ }^{28} \mathrm{~A}$ full factorial design is generally regarded as an optimal design to estimate all main effects as well as all interaction effects. However, a full factorial design is rarely feasible depending on the final number of attributes and levels. Thus, we might have to opt for the largest possible fractional factorial design with a high D-efficiency. We will use SAS V. 9.4 to construct the choice sets of the DCE. We chose to construct a labelled 
DCE for our study, which uses specific labels or titles for the different alternatives, thus already conveying information to the study participants. For this study, the label 'type of care' will be used, categorised into 'only informal care', 'mix of informal and formal/outpatient care' and 'only formal/outpatient care'. While labelled DCEs are currently less frequently used in health economics, alternatives will be less abstract and more realistic for respondents, adding to the validity of the results. ${ }^{31}$

Results from the systematic literature review, as well as the interviews, will be used to establish the attributes for the DCE. In total, four to six attributes will be created on the basis of their relevance to the research question and decision context. ${ }^{18}$ In the creation of the attributes, particular focus will be placed on the independence of attributes. We would like to respectively include at least one attribute connected to cost (or time). The willingness to pay for services will be integrated as an attribute in the DCE. Other potential attributes might be quality of care or retention of autonomy. With the selection of included attributes, the corresponding range of levels for each attribute will also be decided on and discussed with experts. No opt-out option will be included in the profiles to ensure the complete estimation of preference structures and trade-offs made between choice sets. Additionally, the option of not providing needed care is no realistic scenario in this case.

\section{Data collection and sampling strategy}

For the sample, people between 18 and 65 years of age will be recruited from the German general population with no own need for care. The aim of the age limit is the ascertainability of a group of people of working age with no own dependency on care. Occupational and familial obligations are expected to influence the individual willingness to provide care for relatives. Study participants will be recruited in cooperation with a statutory health insurance (AOK Lower Saxony) by random selection of insured Germans in the chosen age range. Particular attention will be placed on the population group 45-64 years of age, as they most likely have own informal caregiving experiences. The primary mode of administration will be a mail survey. Study participants will receive detailed information about the study and the data management plan beforehand. Data will only be used after written informed consent by all study participants. In accordance with the new European General Data Protection Regulation, the statutory health insurance will be in charge of recruitment and contacting potential study participants. We will only receive the filled out questionnaires of study participants after written informed consent has been obtained. All personal data, that is, sociodemographic characteristics, will be provided to us in a pseudonymised manner. ${ }^{32}$ Based on the first estimations, the targeted sample size is approximately 250 per questionnaire version. ${ }^{33}$ Calculating with two questionnaire versions and estimating with a response rate of $1 / 3$, we would send out about 1500 questionnaires. To verify these first estimations, we will use the sample size calculations by de Bekker-Grob et al. This approach consists of five elements that are deemed necessary for calculating the required sample size of a DCE. Particularly, the significance level, the statistical power, the statistical model used in the DCE, initial beliefs about parameter values and the DCE design itself are needed. ${ }^{24}$

Once all the attributes, descriptions and levels, as well as the different choice sets have been established, we will perform a pretest $(n=20)$ to make sure the questionnaire is understandable for study participants. Next to the understanding of attributes and their levels, we will also test the length and complexity of the DCE questionnaire. A rationality test will be included in the survey to make sure study participants understand the questions. After making any necessary adjustments to the questionnaire following the pretest, we will be able to send out the final survey. Next to the DCE choice sets, we will ask participants to disclose a number of important sociodemographic factors, as well as provide an assessment of their perceived quality of life. This data will then be used in the analysis of the questionnaires. To measure the health-related quality of life of study participants, we will use the standardised 5-level EQ-5D (EQ-5D-5L) instrument introduced by the EuroQol Group in 2009, consisting of the five dimensions mobility, self-care, usual activities, pain/ discomfort and anxiety/depression. Next to the descriptive system of the instrument, comprised of the five dimensions with five severity levels each, respondents will also be asked to judge their current health state on a Visual Analogue Scale from 0 to $100 .^{34}$

\section{Data analysis of DCE}

Following data collection, we will analyse the data with descriptive statistics and conduct several logistic regression analyses to determine factors that influenced the choices made by the study participants. We will analyse and compare the distribution of mean age and sex between the included respondents of the DCE and the people who did not respond. The core of the statistical analysis rests on the random utility theory, in which choices can be divided into an explainable component and a random component and people's preferences are summarised by their utility function. ${ }^{24}$ The random component can be due to different types of error, unobservable attributes or preference variation. ${ }^{17}$ The assumption is that people choose the option with the highest utility. For the multivariate analyses, we will use a mixed multinomial logit regression model and a latent class finite mixture model. Both multivariate analyses are appropriate to compare subgroups and see if factors such as gender, age and previous caregiving experience influence the choices made. We chose to perform a multinomial logit model, as our dependent variable (type of care) has more than two levels. Additionally, we will conduct a latent class finite mixture model, which allows the identification of latent classes or subgroups within the sample with different preference weights. ${ }^{35}$ With the statistical 
analyses, we aim to investigate if certain sociodemographic characteristics or previous caregiving experiences influence the choices made by the study participants with regard to care preferences. The statistical program $\mathrm{R}$ will be used to perform all statistical analyses.

\section{Patient and public involvement}

The development of the research question and outcome measures were informed by the current demographic changes and political efforts in Germany, as well as the lack of preference studies in the field of elderly care in Germany. No patients or members of the public were involved in the design of the study. The public will be involved during the design of the questionnaire, as well as the conduction of the DCE. The results of the face-toface interviews will be sent and disseminated to the study participants. The results of the systematic literature review and the DCE will be published in open-access journals.

\section{ETHICAL CONSIDERATIONS AND DISSEMINATION}

The study has been registered at the German Registry of Clinical Trials (DRKS00012266) and is already visible on the WHO International Clinical Trials Registry Platform. A contact person will be provided for all participants in the event of questions or later withdrawal from the study. The results of the study will be discussed and disseminated to relevant stakeholders in the field. Important experts are for instance payers, care providers and lobbyists. Outcomes in the form of recommendations regarding a more efficient use of the limited resources available will also be made by taking into consideration the preferences of the German general population. We will subsequently publish the results in peer-reviewed scientific journals.

\section{DISCUSSION}

Elderly people in need of care are expected to increase from 2.4 million in 2015 to 4.4 million in 2060 due to changing demographics, rising numbers of multimorbidities and increasing life expectancy. Of the 4.4 million elderly Germans in need of care in 2060, the group aged $80+$ is projected to make up $74 \%$ in total. ${ }^{3}$ At the same time, current demographic and societal changes will likely make informal caregiving more challenging in the future and the subsequent demand for long-term care facilities is unlikely to be met. To reduce the growing expenses of the long-term care insurance in Germany, political efforts have previously encouraged informal caregiving and the use of outpatient services to prolong caregiving at home. In the most recent care support act of 2017, the state increased monetary support for caregiving at home and aimed to facilitate the agreement of caregiving and professional responsibilities for informal caregivers. However, insufficient research has been done in Germany to see if political efforts match the wishes and needs of informal caregivers and to representatively measure the preferences of (potential) informal caregivers.

The results from this study will provide an important source of information towards improving the German care structures and payment systems to accommodate future demographic and societal trends. Our analysis will address the aims of this study by providing estimates of the importance of each attribute/care characteristic for the overall preference of the type of care. Additionally, the study will provide an indication to which extent people are willing to trade-off between attributes. Several logistic regression models will be used to analyse subgroup differences in preferences, such as sociodemographic factors, previous informal caregiving experiences or migrant background. The outputs of the study will be critically discussed and disseminated to stakeholders in the field to spark political debate. Suggested solutions will be made to improve the current care structures and use available resources more efficiently. Available care services for informal caregivers can be improved preference based to further encourage and facilitate caregiving at home. Additionally, the surveyed willingness to provide care and willingness to pay for services of the German general population can be used to better tailor existing services. This study will be the first in Germany to use a (labelled) DCE to elicit people's caregiving preferences for care characteristics such as time and cost.

Contributors LdJ, KD, MP and JZ were involved in the design of the study. JTS and SE were responsible for the design of the recruitment process. LdJ was responsible for drafting the manuscript. All authors approved the final study design and were involved in revising the manuscript. All authors agree to be accountable for all aspects of the work

Funding This work was supported by the Federal Ministry of Education and Research, grant number 01EH1603A. The publication of this article was funded by the Open Access Fund of the Leibniz University Hannover.

Competing interests None declared.

Patient consent for publication Not required.

Ethics approval The study has been approved by the Medizinische Hochschule Hannover (MHH)'s Committee for Clinical Ethics (Reference number 09.05.17/La).

Provenance and peer review Not commissioned; externally peer reviewed.

Open access This is an open access article distributed in accordance with the Creative Commons Attribution Non Commercial (CC BY-NC 4.0) license, which permits others to distribute, remix, adapt, build upon this work non-commercially, and license their derivative works on different terms, provided the original work is properly cited, appropriate credit is given, any changes made indicated, and the use is non-commercial. See: http://creativecommons.org/licenses/by-nc/4.0/.

\section{REFERENCES}

1. Matthews Z, Channon A. Will there be enough people to care? Notes on workforce implications of demographic change 2005 - 2050. Geneva: Evidence and Information for Policy, Organisation Mondiale de la santé, 2006.

2. Destatis. Pflegestatistik 2015: Pflege im Rahmen der Pflegeversicherung Deutschlandergebnisse. Wiesbaden, 2017.

3. Bundesinstitut für Bevölkerungsforschung. Zahlen und Fakten: Anzahl der Pflegebedürftigen steigt vor allem bei den Hochbetagten: Pflegebedürftige nach Altersgruppen, 1999-2060. 2017 http://www. demografie-portal.de/SharedDocs/Informieren/DE/ZahlenFakten/ Pflegebeduerftige_Anzahl.html (Accessed 23 Aug 2018).

4. Rothgang $\mathrm{H}$, Müller R, Unger $\mathrm{R}$, et al. Themenreport Pflege 2030: Was ist zu erwarten - was ist zu tun? Bertelsmann Stiftung, 2012. 
5. Bundesministerium für Gesundheit. Sechster Bericht der Bundesregierung über die Entwicklung der Pflegeversicherung und den Stand der pflegerischen Versorgung in der Bundesrepublik Deutschland. https://www.bundesgesundheitsministerium.de/ fileadmin/Dateien/5_Publikationen/Pflege/Berichte/6.Pflegebericht. pdf (Accessed 23 Aug 2018).

6. Bundesinstitut für Bevölkerungsforschung. Zahlen und Fakten: Pflegebedürftige werden meistens zu Hause versorgt. 2017 http://www.demografie-portal.de/SharedDocs/Informieren/DE/ ZahlenFakten/Pflegebeduerftige_Versorgung.html (Accessed 23 Aug 2018).

7. Heuchert M, König HH, Lehnert T. The role of preferences in the German long-term care insurance - results from expert interviews. Gesundheitswesen 2017;79:1052-7.

8. Hajek A, Lehnert T, Wegener A, et al. Potential for informal care of the elderly in Germany: results of a representative population-based survey. Z Gerontol Geriatr 2018;51:612-9.

9. Hajek A, Lehnert T, Wegener A, et al. Factors associated with preferences for long-term care settings in old age: evidence from a population-based survey in Germany. BMC Health Serv Res 2017;17:1-9.

10. Hajek A, Brettschneider C, Ernst A, et al. Longitudinal predictors of informal and formal caregiving time in community-dwelling dementia patients. Soc Psychiatry Psychiatr Epidemiol 2016;51:607-16.

11. Geyer J, Schulz E. Who cares?: Die Bedeutung der informellen Pflege durch Erwerbstätige in Deutschland, DIW-Wochenbericht. 2014;81:294-301.

12. Haley WE. Family caregivers of elderly patients with cancer: understanding and minimizing the burden of care. J Support Oncol 2003;1(4 Suppl 2):25-9.

13. Schneider U. Informelle Pflege aus ökonomischer Sicht. Zeitschrift für Sozialreform 2006;52:493-520.

14. Kemper $P$. The use of formal and informal home care by the disabled elderly. Health Serv Res 1992;27:421-51.

15. Spangenberg L, Glaesmer H, Brähler E, et al. Use of family resources in future need of care. Care preferences and expected willingness of providing care among relatives: a population-based study. Bundesgesundheitsblatt Gesundheitsforschung Gesundheitsschutz 2012:55:954-60.

16. van den Berg B, Brouwer WB, Koopmanschap MA. Economic valuation of informal care. An overview of methods and applications. Eur J Health Econ 2004;5:36-45.

17. Lancsar E, Louviere J. Conducting discrete choice experiments to inform healthcare decision making: a user's guide. Pharmacoeconomics 2008;26:661-77.

18. Bridges JF, Hauber AB, Marshall D, et al. Conjoint analysis applications in health-a checklist: a report of the ISPOR Good Research Practices for Conjoint Analysis Task Force. Value Health 2011;14:403-13.

19. Moher D, Liberati A, Tetzlaff $J$, et al. Preferred reporting items for systematic reviews and meta-analyses: the PRISMA statement. $J$ Clin Epidemiol 2009;62:1006-12.
20. Palinkas LA, Horwitz SM, Green CA, et al. Purposeful sampling for qualitative data collection and analysis in mixed method implementation research. Adm Policy Ment Health 2015;42:533-44.

21. Glaser BG, Strauss AL, Paul AT. Grounded theory: Strategien qualitativer Forschung. 1st edn. Bern: Huber, 2008.

22. Mayring P. Qualitative Inhaltsanalyse: Grundlagen und Techniken. s.I: Beltz Verlagsgruppe. 2010.

23. Hsieh HF, Shannon SE. Three approaches to qualitative content analysis. Qual Health Res 2005;15:1277-88.

24. de Bekker-Grob EW, Donkers B, Jonker MF, et al. Sample size requirements for discrete-choice experiments in healthcare: a practical guide. Patient 2015;8:373-84

25. Ryan M, Bate A, Eastmond CJ, et al. Use of discrete choice experiments to elicit preferences. Quality and Safety in Health Care 2001;10(Supplement 1):i55-60.

26. de Bekker-Grob EW, Ryan M, Gerard K. Discrete choice experiments in health economics: a review of the literature. Health Econ 2012;21:145-72.

27. Coast J, Horrocks S. Developing attributes and levels for discrete choice experiments using qualitative methods. J Health Serv Res Policy 2007:12:25-30.

28. Street DJ, Burgess L, Louviere JJ. Quick and easy choice sets: constructing optimal and nearly optimal stated choice experiments. Int J Res Mark 2005;22:459-70.

29. Burgess L, Street DJ. Optimal designs for choice experiments with asymmetric attributes. J Stat Plan Inference 2005;134:288-301.

30. Reed Johnson F, Lancsar E, Marshall D, et al. Constructing experimental designs for discrete-choice experiments: report of the ISPOR Conjoint analysis experimental design good research practices task force. Value Health 2013;16:3-13.

31. de Bekker-Grob EW, Hol L, Donkers B, et al. Labeled versus unlabeled discrete choice experiments in health economics: an application to colorectal cancer screening. Value Health 2010;13:315-23.

32. EUR-Lex. Regulation (EU) 2016/679 of the European Parliament and of the Council of 27 April 2016 on the protection of natural persons with regard to the processing of personal data and on the free movement of such data, and repealing Directive 95/46/ EC (General Data Protection Regulation): CELEX no. 32016R0679. 2016.

33. Orme B. Getting started with conjoint analysis: strategies for product design and pricing research. Madison, Wis: Research Publishers LLC, 2010.

34. van Reenen M, Janssen B. EQ-5D-5L User guide: basic information on how to use the EQ-5D-5L instrument. 2015 (Accessed 23 Aug 2018).

35. Hauber AB, González JM, Groothuis-Oudshoorn CG, et al. Statistical methods for the analysis of discrete choice experiments: a report of the ispor conjoint analysis good research practices task force. Value Health 2016;19:300-15. 